\title{
Photonic Crystal Surface Emitting Laser Operating in Pulse-Periodic Regime with Ultralow Divergence Angle
}

\author{
Ziye Wang ${ }^{1,2}$, Cunzhu Tong ${ }^{1, *}$, Lijie Wang ${ }^{1}$, Huanyu $\mathrm{Lu}^{1,2}{ }^{1,}$ Sicong Tian ${ }^{1}$ and Lijun Wang ${ }^{1}$ \\ 1 State Key Laboratory of Luminescence and Applications, Changchun Institute of Optics, Fine Mechanics and \\ Physics, Chinese Academy of Sciences, Changchun 130033, China; wangziye17@mails.ucas.edu.cn (Z.W.); \\ wanglijie@ciomp.ac.cn (L.W.); luhuanyu@ciomp.ac.cn (H.L.); tiansicong@ciomp.ac.cn (S.T.); \\ wanglj@ciomp.ac.cn (L.W.) \\ 2 Center of Materials Science and Optoelectronics Engineering, University of Chinese Academy of Sciences, \\ Beijing 100049, China \\ * Correspondence: tongcz@ciomp.ac.cn
}

\section{check for}

updates

Citation: Wang, Z.; Tong, C.; Wang, L.; Lu, H.; Tian, S.; Wang, L. Photonic Crystal Surface Emitting Laser Operating in Pulse-Periodic Regime with Ultralow Divergence Angle. Photonics 2021, 8, 323. https:// doi.org/10.3390/photonics 8080323

Received: 25 June 2021

Accepted: 3 August 2021

Published: 10 August 2021

Publisher's Note: MDPI stays neutral with regard to jurisdictional claims in published maps and institutional affiliations.

Copyright: (C) 2021 by the authors Licensee MDPI, Basel, Switzerland. This article is an open access article distributed under the terms and conditions of the Creative Commons Attribution (CC BY) license (https:// creativecommons.org/licenses/by/ $4.0 /)$.

\begin{abstract}
The nanosecond-level pulse-operation characteristics of photonic-crystal surface-emitting lasers (PCSELs) with ultralow divergence were investigated in detail. We demonstrate a maximum peak output power of $14 \mathrm{~W}$ for a current pulse width of $9 \mathrm{~ns}$, which is about 28 times the saturated power under continuous wave (CW) operation. The full width at half maximum (FWHM) of the optical response pulse is about $3 \mathrm{~ns}$ wider than the current pulse. The maximum repetition frequency reaches $400 \mathrm{kHz}$ at $10 \mathrm{~A}$ without significant degradation of output power while the value is $100 \mathrm{kHz}$ at $40 \mathrm{~A}$. Moreover, the multimode behavior of the PCSEL at a high peak current was analyzed.
\end{abstract}

Keywords: photonic crystal; surface-emitting lasers; pulse operation; ultralow divergence

\section{Introduction}

The light detection and ranging (LiDAR) system, converting distance measurements into signal pulses, has promising applications in driverless vehicles, atmosphere observing, etc. The optical sources of LiDAR can be solid-state lasers [1,2], fiber lasers [3,4] and semiconductor lasers [5-7], and are expected to have high peak power [8], high repetition frequency [9], short pulse width [9], and low beam divergence angle [10]. Compared with solid-state lasers and fiber lasers, the semiconductor lasers show a low cost, small volume, easy integration, and the highest conversion efficiency among these laser sources. Therefore, semiconductor lasers are a promising laser source for the LiDAR system. However, traditional semiconductor lasers like edge-emitting lasers also suffer from some disadvantages, such as the large divergence angle and elliptic beam. The respective optical collimation would be required for slow and fast axes and increase the cost significantly, especially for 64 lines, 128 lines, or more lines LiDAR. Increasing the number of lines that are aimed to obtain higher-resolution imaging puts forward higher requirements for the divergence angle of the light source and the portability and integration of devices. Although the vertical-cavity surface-emitting laser (VCSEL), a kind of semiconductor laser, emits a circular symmetrical beam [11-13], it generates high-order modes for high power emission and the divergence angle is in the order of $10^{\circ}[14,15]$.

PCSELs are a kind of novel surface-emitting semiconductor lasers, which have not only the typical advantages of surface-emitting lasers but also the single-lobed narrow beam with higher output power [16-20] attributed to the large-area coherent resonance. Hence, studying the characteristics of PCSELs under pulsed conditions is significant for providing efficient, stable and no-collimation required laser sources for LiDAR system where several nanosecond long optical pulses are needed [21]. The short pulse width is important for obtaining enough detecting precision and ensuring eye safety, especially for wavelengths less than $1.5 \mu \mathrm{m}$ [9]. However, until now, it has lacked detailed investigation 
in this regard, although their other properties such as polarization and beam pattern have been discussed previously [22-25].

Here, we systematically studied the characteristics of PCSELs injected with a pulse current of several nanoseconds, including the light-current characteristics, pulse waveforms, and lasing spectra. The divergence angles and responsive optical pulses were measured and discussed. The impact of different repetition frequencies and pulse widths on the peak power was analyzed.

\section{Sample Structure and Lasing Principles}

The epitaxial structure of the PCSEL [18] investigated here includes AlGaAs ncladding layer, InGaAs muti-quantum wells (MQWs), AlGaAs blocking layer, air/GaAs photonic crystal layer, AlGaAs p-cladding layer and GaAs p-contact layer. The squarelattice photonic crystal was fabricated near the active layer as shown in Figure 1. The photonic crystal acts as the resonant cavity through two-dimensional Bragg diffraction. Moreover, to allow the light diffracted by the photonic crystal to be emitted from the surface, a square light-output window with a side length of $340 \mu \mathrm{m}$ was retained when n-electrode was deposited.

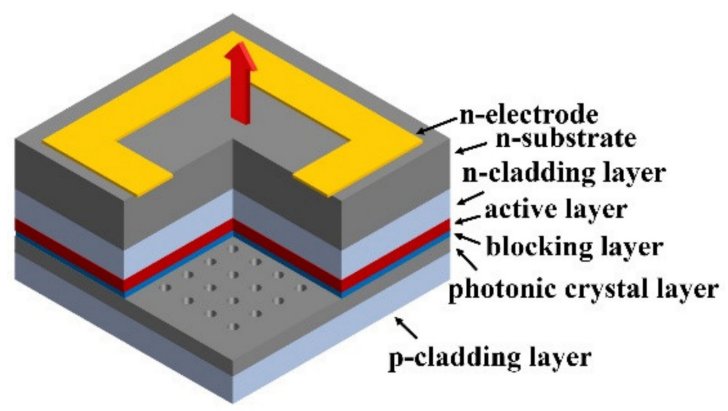

Figure 1. Schematic structural diagram of the PCSEL.

The operation principles of PCSELs are described in Figure 2. Figure 2a shows the structure of photonic crystal embedded in the waveguide layer of PCSEL. Each gray circle in the figure represents a lattice point. The yellow arrows represent the optical wave propagating in the plane, and the red arrows represent the diffracted optical wave towards the vertical direction. The majority of the optical field oscillating in the resonant cavity propagates in-plane, and the standing waves are formed in a large area once the Bragg condition is satisfied. However, some of the light can also be diffracted into the vertical direction, which leads to the surface emission.

Figure $2 \mathrm{~b}$ sketches the wave vector diagram and Bragg diffraction condition at $\Gamma$ point of the photonic-band structure. The black arrows represent the basic vectors of photonic crystal with square lattice in reciprocal space. The yellow arrows represent the in-plane wave vectors without any vertical components. Among them, the arrow labeled as $k_{i}$ means the incident wave vector and the other three arrows mean diffracted wave vectors in correspondence with the Bragg condition. The red arrow represents the wave vector vertical to the photonic crystal plane, contributing to the surface emission. The first Brillouin zone is shown as a blue frame. All these wave vectors obey the Bragg diffraction condition, which means that the difference between incident wave vector $k_{i}$ and in-plane component $k_{d}$ of all other diffracted wave vectors should be a multiple of basic vector $k_{1}$ and $k_{2}$. When $\mathbf{k}_{d}=\mathbf{k}_{i}-\mathbf{k}_{2}$, the in-plane component of the diffracted wave vector is zero, which means the total wave vector is vertical to the plane, and then surface emission happens.

The band diagram of the PCSEL for TE mode was calculated using a plane-wave expansion method [26] as shown in Figure 2c. The bands were calculated with three-dimensional simulations. The structural parameters used in the calculation are provided in Table 1. The lattice constant of the photonic crystal is $277 \mathrm{~nm}$. Air holes were 
fabricated in the photonic crystal layer. The filling factor and depth of the air holes are $13 \%$ and $160 \mathrm{~nm}$, respectively. The filling factor is defined as the percent of area occupied by the air holes. The detailed structure in the vicinity of $\Gamma$ consists of four bands. The group velocity of light at the band edge is zero, which means that the standing wave is formed at this point. Zero group velocity also ensures the lowest in-plane radiation loss and thus the lowest lasing threshold. Therefore, surface emission tends to exist at this point. By adjusting the frequency corresponding to the band edge, it can realize the output of light with different wavelengths $[19,20,27,28]$.
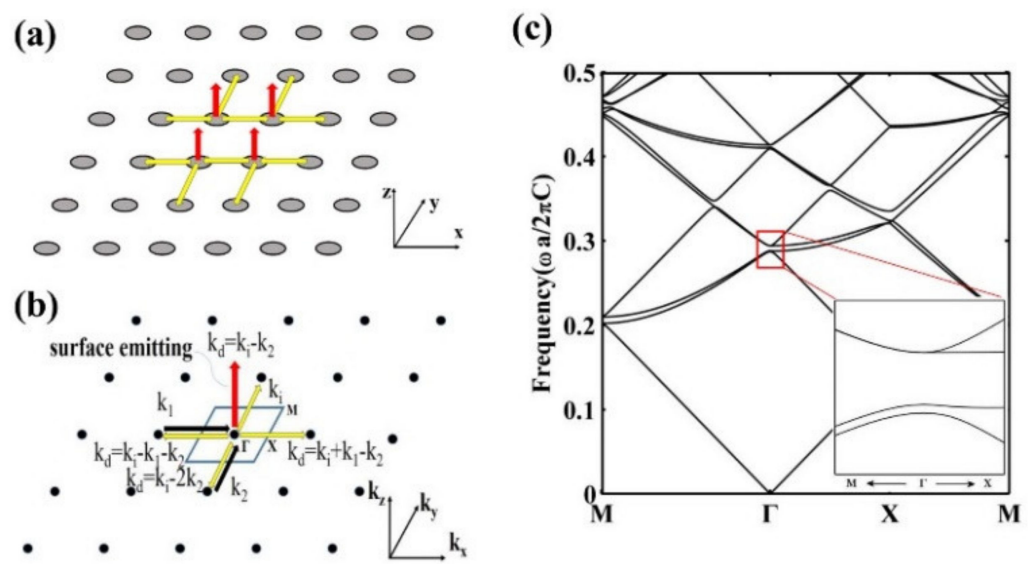

Figure 2. Lasing principles of PCSELs. (a) Schematic diagram of square-lattice photonic crystal. The yellow arrows indicate light diffracted in-plane. The red arrows indicate light diffracted into vertical direction. (b) Wave vector diagram of the photonic crystal and Bragg diffraction condition at $\Gamma$ point. (c) The band diagram of the PCSEL calculated by a plane-wave expansion method. The inset shows the detailed bands in the vicinity of $\Gamma$.

Table 1. Structural parameters of the PCSEL.

\begin{tabular}{ccc}
\hline Layer & Thickness $(\mathbf{n m})$ & Refractive Index \\
\hline n-cladding layer & 1500 & $3.20(\mathrm{AlGaAs})$ \\
MQWs & 98 & $3.52(\mathrm{InGaAs} / \mathrm{AlGaAs})$ \\
blocking layer & 60 & $3.19(\mathrm{AlGaAs})$ \\
photonic crystal layer & 180 & $3.55(\mathrm{GaAs})$ \\
p-cladding layer & 1500 & $3.28(\mathrm{AlGaAs})$ \\
p-contact layer & 210 & $3.55(\mathrm{GaAs})$ \\
\hline
\end{tabular}

\section{Results and Discussion}

The laser characteristics of the PCSEL under CW operation are shown in Figure 3. Figure 3a illustrates light-current characteristics for varying operating temperatures from $20^{\circ} \mathrm{C}$ to $60^{\circ} \mathrm{C}$. Significant rollover due to self-heating can be observed at a high current for all temperatures. With increasing temperature, the slope efficiency also decreases gradually. In order to evaluate the influence of thermal effect on the performance of the device, saturated output power and threshold current as functions of temperature are illustrated in Figure $3 \mathrm{~b}$. The saturated output power is $500 \mathrm{~mW}$ at $20^{\circ} \mathrm{C}$ while the value is only $76 \mathrm{~mW}$ at $60{ }^{\circ} \mathrm{C}$. The decreasing rate is about $10.6 \mathrm{~mW} /{ }^{\circ} \mathrm{C}$. The slope efficiency and threshold current of the device at $20^{\circ} \mathrm{C}$ are $0.43 \mathrm{~W} / \mathrm{A}$ and $212 \mathrm{~mA}$, respectively. The temperature-dependent threshold current $I_{\text {th }}$ can be evaluated by formula as follows [20]:

$$
I_{\mathrm{th}}(T)=I_{\mathrm{th}}\left(T_{1}\right) \exp \left[\left(T-T_{1}\right) / T_{0}\right],
$$

where $T$ is the operating temperature, $T_{0}$ is the characteristic temperature. As shown in Figure $3 \mathrm{~b}$, the calculated characteristic temperature of the PCSEL is $222 \mathrm{~K}$ in the range of $20-40{ }^{\circ} \mathrm{C}$ and $53 \mathrm{~K}$ in the range of $40-60{ }^{\circ} \mathrm{C}$. 

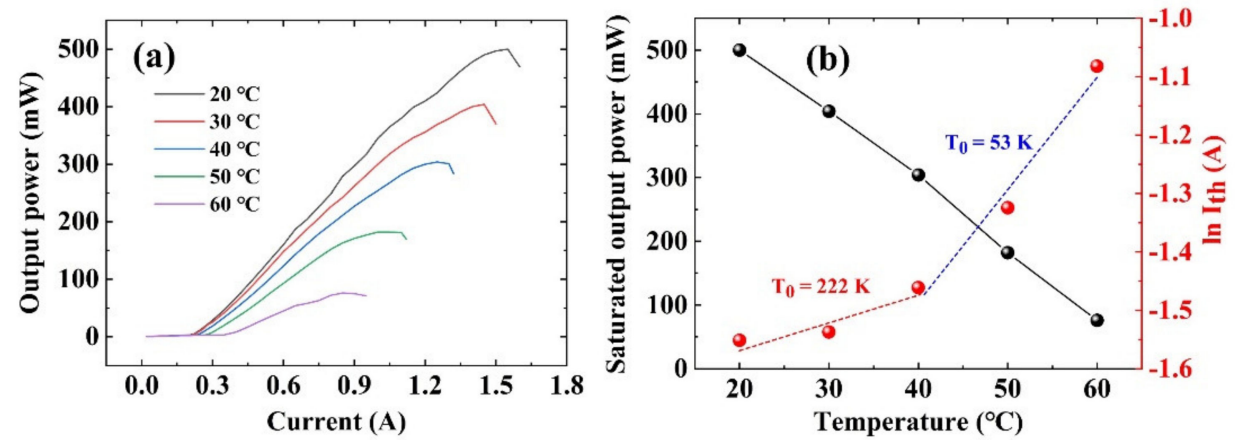

Figure 3. Laser characteristics of the PSCEL under CW operation. (a) Light-current characteristics for varying temperatures from $20^{\circ} \mathrm{C}$ to $60^{\circ} \mathrm{C}$ in steps of $10^{\circ} \mathrm{C}$. (b) Saturated output power and threshold current versus operating temperature. $T_{0}$ is the characteristic temperature.

Figure 4 shows the beam properties of the device. The far-field patterns measured directly at distances of $5 \mathrm{~cm}$ to $1 \mathrm{~m}$ without any lenses are shown in Figure $4 \mathrm{a}$. The injected current is $0.3 \mathrm{~A}$. The detecting area of the detector is $9 \mathrm{~mm} \times 9 \mathrm{~mm}$. It can be seen that the far-field pattern is symmetric and approximately circular, and increases from a very small beam. The beam size is still less than $9 \mathrm{~mm} \times 9 \mathrm{~mm}$ even at a $1-\mathrm{m}$ distance, which reveals the divergence is quite low.
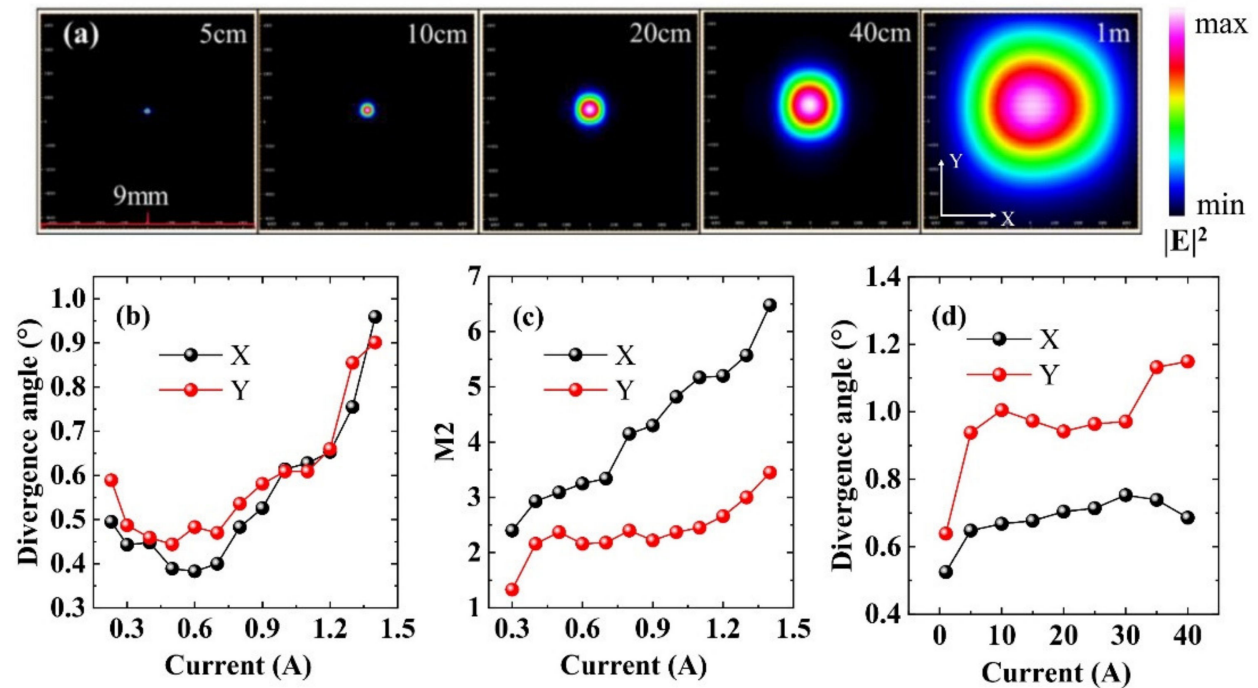

Figure 4. Beam properties of the PCSEL. (a) The measured far-field patterns at different distances from the emitting surface without any lenses under CW operation. (b) Divergence angle and (c) beam quality as a function of injected current under CW operation. (d) Divergence angle as a function of injected current under pulse operation with repetition frequency of $5 \mathrm{kHz}$ and pulse width of $9 \mathrm{~ns}$.

Figure $4 \mathrm{~b}, \mathrm{c}$ illustrate the full divergence angles and beam quality $\mathrm{M}^{2}$ factor as a function of injected current, which were measured respectively by the $1 / \mathrm{e}^{2}$ and $4-$ sigma method (ISO) $[29,30]$ using Thorlabs $\mathrm{M}^{2}$ measurement systems (M2MS). It indicates that the full divergence angle is in the range from $0.38^{\circ}$ to $0.96^{\circ}$, which decreases firstly with the increasing current and then tends to be stable. When the current is above $0.7 \mathrm{~A}$, the divergence angle increases again due to the emergence of high-order modes. The values of divergence angle at $0.7 \mathrm{~A}$ are respectively $0.40^{\circ}$ and $0.47^{\circ}$ for $\mathrm{X}$ and $\mathrm{Y}$ axes. The measuring resolution is $0.001^{\circ}$. The $\mathrm{M}^{2}$ factor keeps increasing gradually with the increasing injected current, and the values in vertical and lateral directions are almost at the same increasing rate. However, prior to the vertical direction, the $\mathrm{M}^{2}$ factor of the lateral direction tends to increase rapidly above $0.7 \mathrm{~A}$, which means that the earlier emergency of the high order modes in this direction. The $\mathrm{M}^{2}$ values are in the range of 1.33 to 6.48 at injected current 
from $0.3 \mathrm{~A}$ to $1.5 \mathrm{~A}$. According to the definition of the $\mathrm{M}^{2}$ factor which is in direct proportion to the product of divergence angle and beam waist, it can deduce that the beam waist increases with the injected current at the beginning. The phenomenon that divergence decreases firstly and then is stable might be because of the inhomogeneous injection of current due to the large injection window. When the current is just above the threshold, this inhomogeneous injection makes the spatial gain distribution of the light field quite different, which leads to relatively poor spatial coherence and a large divergence angle. However, with the increase in current, the gain distribution and spatial coherence become better and the divergence angle decreases gradually. Figure $4 \mathrm{~d}$ shows the divergence angle under pulse operation with a repetition frequency of $5 \mathrm{kHz}$ and pulse width of $9 \mathrm{~ns}$. The values are about $0.7^{\circ}$ and $1.0^{\circ}$ for the $\mathrm{X}$ and $\mathrm{Y}$ axes, respectively. It should be noted that the divergence angle of the Gaussian beam can be calculated by formula as follows:

$$
\theta=2 \lambda /(\pi \omega),
$$

where $\lambda$ is the wavelength of light, $\omega$ is the beam waist. If we assume a beam waist of $340 \mu \mathrm{m}$ and a wavelength of $937 \mathrm{~nm}$, the divergence angle for an ideal Gaussian beam would be $0.20^{\circ}$.

Figure 5 shows lasing characteristics of the PCSEL with different pulse widths. The device is driven by diode driver EPC9126HC from Efficient Power Conversion Corporation. The power is measured by photodiode power sensors S145C from Thorlabs. The electrical signals in the time domain are measured with oscilloscope MDO3000 from Tektronix. The optical signals in the time domain are measured with InGaAs biased detector DET08C/M from Thorlabs. All the measurements are under a pulse repetition frequency of $1 \mathrm{kHz}$. The peak output power and corresponding average power are shown in Figure 5a,b, respectively. The peak output power is given by

$$
P_{\text {peak }}=P_{\text {av }} /\left(f \cdot t_{\mathrm{w}}\right),
$$

where $P_{\mathrm{av}}$ is the average power, $f$ is the repetition frequency, $t_{\mathrm{w}}$ is the effective optical response pulse width defined as the ratio between the waveform's integral area and its peak intensity. The current pulse width was estimated by the FWHM of the first peak. From Figure 5a, it can be found that when the current pulse width is $5 \mathrm{~ns}$ and $6 \mathrm{~ns}$, the peak output power of the optical response pulse tends to be saturated at a current above $30 \mathrm{~A}$. The saturation might owe to the special current pulse waveform which is mainly determined by inherent properties of the driving circuit and parasitic parameters of the loads, as shown in Figure $5 \mathrm{c}$. It should also be noted that the smaller the pulse width, the lower the peak current. In contrast, when driving by pulse current with a width of $9 \mathrm{~ns}$, the peak output power keeps increasing without such saturation and reaches a value of $14 \mathrm{~W}$ at 50 A eventually. Figure $5 \mathrm{~d}$ demonstrates the pulse waveform when the current pulse width is $9 \mathrm{~ns}$.

To better understand the optical response behavior of the PCSEL under pulse operation, the optical response pulse waveforms at different currents were studied. As shown in Figure 6a, in the beginning, the waveforms maintain an approximate sine wave shape which is consistent with the waveform of the current pulse. However, the optical pulse intensity becomes quite uneven in the time domain at a current as high as $40 \mathrm{~A}$. In contrast, the corresponding current pulse whose waveform remains stable and about $9 \mathrm{~ns}$ in width is illustrated in the inset of Figure 6a. This owes to the dynamic interaction between carriers and photons. At high injected current, the instantaneous photon density in the resonant cavity is so high that the carrier concentration in the conduction band and the valence band is significantly reduced. Then, the instantaneous photon density and output power decrease rapidly. This leads to a drop in the middle of the waveforms of the optical response pulse. Moreover, the non-uniformity of current injection resulting from the large size and ring-shaped electrode of the PCSEL also enhances this intensity fluctuation in the time domain. Figure $6 \mathrm{~b}$ shows the corresponding optical response pulse width of the 
PCSEL. Both FWHM width and effective width were obtained. It can be found that the FWHM width tends to increase at first with the injected pulse current and then be stable at a value of about $12 \mathrm{~ns}$. The corresponding effective pulse width has a similar trend except for the decrease at a current above $40 \mathrm{~A}$ because of the unevenness of the waveform.
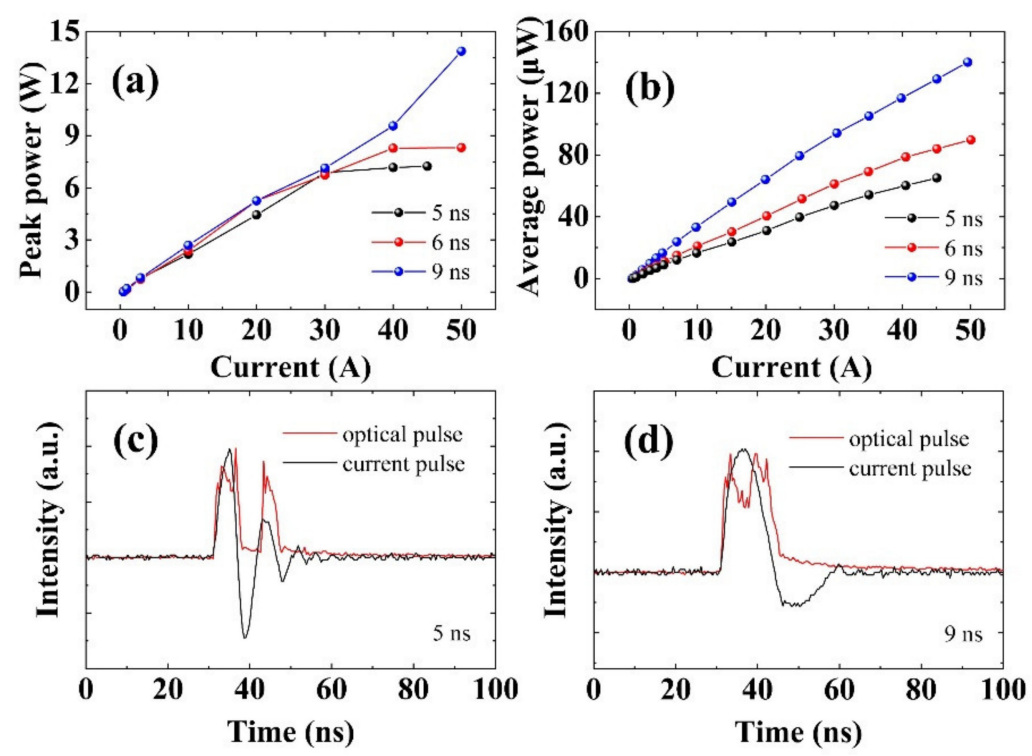

Figure 5. Laser characteristics of the PCSEL under pulse operation modulated at $1 \mathrm{kHz}$. (a) Peak output power versus injected current with different pulse widths. (b) The corresponding average power of (a). (c,d) are the current and optical pulse waveforms injected by current of $40 \mathrm{~A}$ with pulse widths of 5 ns and 9 ns, respectively.
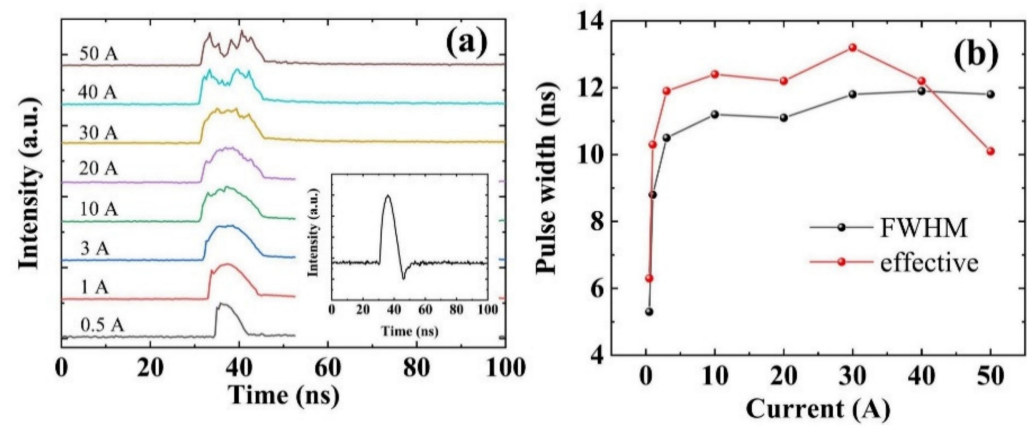

Figure 6. Optical response pulse of the PSCEL under pulse operation. (a) Measured optical pulse waveforms of PSCEL at different injected current when modulated at $1 \mathrm{kHz}$ with a current pulse width of 9 ns. The inset shows the waveform of current pulse with peak value of $20 \mathrm{~A}$. (b) The corresponding optical pulse width of (a).

The effect of repetition frequency on peak output power is also studied as shown in Figure 7. It can be found that when the repetition frequency reaches the magnitude of $100 \mathrm{kHz}$, the peak output power of the device begins to decrease, which might owe to the thermal effect of the device. Moreover, the higher the current pulse is, the earlier the self-heating effect appears. In particular, the peak output power degrades significantly at repetition frequency above $100 \mathrm{kHz}$ when the pulse current is $40 \mathrm{~A}$, while it remains unchanged even at $300 \mathrm{kHz}$ when the pulse current is $10 \mathrm{~A}$. Note that no additional cooling was used here. 


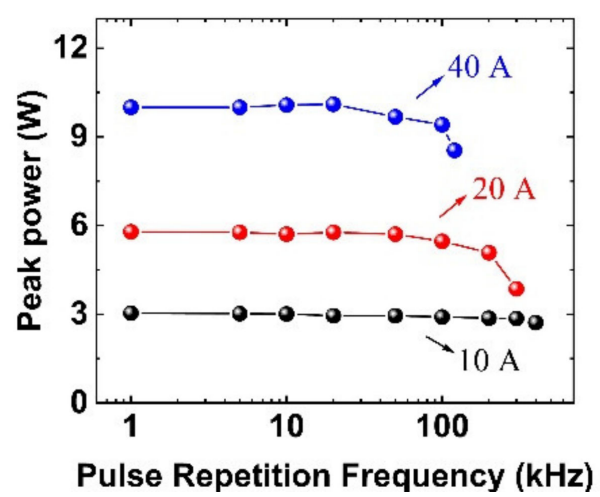

Figure 7. Peak output power of the PSCEL at various repetition frequencies injected by current of $10 \mathrm{~A}, 20 \mathrm{~A}$ and $40 \mathrm{~A}$.

Figure 8 shows the lasing spectra of the PSCEL with different injected currents under $\mathrm{CW}$ and pulse operation. The spectra are measured with spectrometer AQ6370 from Yokogawa Electric Corporation. The narrow linewidth as small as $0.3 \mathrm{~nm}$ of the device helps improve the accuracy of speed measurement in LiDAR application. The side mode suppression ratio (SMSR) under pulse operation for current of $40 \mathrm{~A}$ is $8 \mathrm{~dB}$ while the SMSR under $\mathrm{CW}$ operation for current of $1.2 \mathrm{~A}$ is $14 \mathrm{~dB}$. Moreover, unlike $\mathrm{CW}$ operation, there is almost no wavelength drift under pulse operation indicating no significant temperature rise in the active region. This is due to less heat generation and enough time for heat dissipation under pulse operation with a low repetition frequency. However, side modes appear at large current and tend to exceed the intensity of the fundamental mode. There are two reasons for this phenomenon. Firstly, a large injected current satisfies the threshold above which the side modes can lase. Because these side modes have a higher vertical radiation constant, their vertical output power is naturally higher than the fundamental mode. Secondly, the power redistribution between different oscillation modes is slow under pulse operation. In this condition, the process of mode selection can hardly keep up with the rapidly changing current. Both reasons promote the generation of side modes.

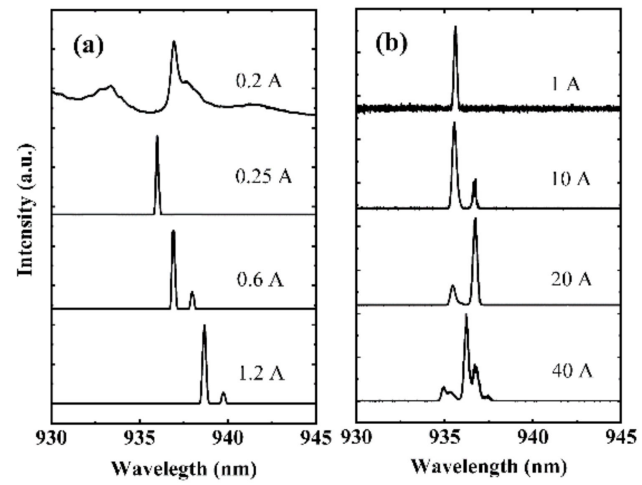

Figure 8. Lasing spectra of PSCEL with different injected current. (a) Under CW operation. (b) Under pulse operation with repetition frequency of $1 \mathrm{kHz}$.

\section{Conclusions}

In summary, several-nanosecond pulse-operation characteristics of PCSELs with ultralow divergence angle were investigated in detail and compared with $\mathrm{CW}$ operation. A maximum peak output power of $14 \mathrm{~W}$ for a current pulse width of $9 \mathrm{~ns}$ was demonstrated, which is about 28 times the saturated power under $\mathrm{CW}$ operation. The pulse width of the optical response pulse is about $3 \mathrm{~ns}$ wider than the current pulse. The maximum repetition frequency reaches $400 \mathrm{kHz}$ at $10 \mathrm{~A}$ without significant degradation of output power, while the value is $100 \mathrm{kHz}$ at $40 \mathrm{~A}$. The thermal effect was thought to be the main limitation and investigated under $\mathrm{CW}$ operation. The characteristic temperature of the threshold current 
is $222 \mathrm{~K}$ in the range of $20-40{ }^{\circ} \mathrm{C}$ and $53 \mathrm{~K}$ in the range of $40-60{ }^{\circ} \mathrm{C}$. The decreasing rate of saturated output power is about $10.6 \mathrm{~mW} /{ }^{\circ} \mathrm{C}$. Moreover, the multimode behavior of the PCSEL at a high peak current was also analyzed.

Author Contributions: Conceptualization, Z.W. and C.T.; Methodology, L.W. (Lijie Wang); Software, Z.W.; Validation, H.L.; Formal Analysis, Z.W. and C.T.; Investigation, S.T.; Resources, L.W. (Lijun Wang); Writing-Original Draft Preparation, Z.W.; Writing-Review \& Editing, C.T. All authors have read and agreed to the published version of the manuscript.

Funding: This research was funded by the National Natural Science Foundation of China (62025506, 61774153, 61774156), the Jilin Provincial Foundation (Nos. 20190302053GX), CAS Youth Innovation Promotion Association (2018249) and the Opened Fund of the State Key Laboratory of High Power Semiconductor Laser.

Institutional Review Board Statement: Not applicable.

Informed Consent Statement: Not applicable.

Data Availability Statement: The data presented in this study are available on request from the corresponding author.

Conflicts of Interest: The authors declare no competing financial interests.

\section{References}

1. Stoneman, R.C.; Hartman, R.; Malm, A.I.; Gatt, P. Coherent laser radar using eyesafe YAG laser transmitters. Proc. SPIE 2005, 5791, 167-174. [CrossRef]

2. Henderson, S.W.; Suni, P.J.M.; Hale, C.P.; Hannon, S.; Magee, J.R.; Bruns, D.L.; Yuen, E.H. Coherent laser radar at 2 mu $\mathrm{m}$ using solid-state lasers. IEEE Trans. Geosci. Remote Sens. 1993, 31, 4-15. [CrossRef]

3. Shi, X.J.; Sun, J.F.; Jang, P.; Lu, W.; Wang, Q.Q.; Wang, Q. All-fiber coherent laser image Lidar based on phase correction. Opt. Express 2019, 27, 26432-26445. [CrossRef] [PubMed]

4. Canat, G.; Lombard, L.; Dolfi, A.; Valla, M.; Planchat, C.; Augère, B.; Bourdon, P.; Jolivet, V.; Besson, C.; Jaouën, Y.; et al. High Brightness $1.5 \mu \mathrm{m}$ Pulsed Fiber Laser for Lidar: From Fibers to Systems. Fiber Integr. Opt. 2008, 27, 422-439. [CrossRef]

5. Huikari, J.M.T.; Avrutin, E.A.; Ryvkin, B.S.; Nissinen, J.J.; Kostamovaara, J.T. High-Energy Picosecond Pulse Generation by Gain Switching in Asymmetric Waveguide Structure Multiple Quantum Well Lasers. IEEE J. Sel. Top. Quantum Electron. 2015, 21, 189-194. [CrossRef]

6. Kostamovaara, J.; Huikari, J.; Hallman, L.; Nissinen, I.; Nissinen, J.; Rapakko, H.; Avrutin, E.; Ryvkin, B. On Laser Ranging Based on High-Speed/Energy Laser Diode Pulses and Single-Photon Detection Techniques. IEEE Photon. J. 2015, 7, 1-15. [CrossRef]

7. Knigge, A.; Klehr, A.; Wenzel, H.; Zeghuzi, A.; Fricke, J.; Maaßdorf, A.; Liero, A.; Tränkle, G. Wavelength-stabilized high-pulsepower laser diodes for automotive LiDAR. Phys. Status Solidi A 2018, 215, 215. [CrossRef]

8. Yun, J.; Gao, C.X.; Zhu, S.L.; Sun, C.D.; He, H.D.; Feng, L.; Dong, L.J.; Niu, L.Q. High-peak-power, single-mode, nanosecond pulsed, all-fiber laser for high resolution 3D imaging LIDAR system. Chin. Opt. Lett. 2012, 10, 121402-121404. [CrossRef]

9. McManamon, P.F. LiDAR Technologies and Systems; SPIE: Bellingham, WA, USA, 2019.

10. Jiang, L.F.; Lan, T.; Gu, M.X.; Ni, G.Q. Effects of laser beam divergence angle on airborne LIDAR positioning errors. J. Beijing Inst. Technol. 2012, 21, 278-284. [CrossRef]

11. Grundl, T.; Debernardi, P.; Muller, M.; Grasse, C.; Ebert, P.; Geiger, K.; Ortsiefer, M.; Bohm, G.; Meyer, R.; Amann, M.C. Record Single-Mode, High-Power VCSELs by Inhibition of Spatial Hole Burning. IEEE J. Sel. Top. Quantum Electron. 2013, $19,1700913$. [CrossRef]

12. Haglund, A.; Gustavsson, J.S.; Vukusic, J.; Modh, P.; Larsson, A. Single fundamental-mode output power exceeding $6 \mathrm{~mW}$ from VCSELs with a shallow surface relief. IEEE Photon. Technol. Lett. 2004, 16, 368-370. [CrossRef]

13. Shu, S.L.; Hou, G.Y.; Feng, J.; Wang, L.J.; Tian, S.C.; Tong, C.Z.; Wang, L.J. Progress of optically pumped GaSb based semiconductor disk laser. Opto-Electron. Adv. 2018, 1, 17000301-17000309. [CrossRef]

14. Siegman, A.E. Defining, measuring, and optimizing laser beam quality. In Proceedings of the OE/LASE'93: Optics, Electro-Optics, \& Laser Applications in Science\& Engineering, Los Angeles, CA, USA, 17-22 January 1993; pp. 2-12.

15. Siegman, A.E. New developments in laser resonators. In Proceedings of the Optical Resonators, Los Angeles, CA, USA, 1 June 1990; pp. 2-14.

16. Yoshida, M.; de Zoysa, M.; Ishizaki, K.; Tanaka, Y.; Kawasaki, M.; Hatsuda, R.; Song, B.; Gelleta, J.; Noda, S. Double-lattice photonic-crystal resonators enabling high-brightness semiconductor lasers with symmetric narrow-divergence beams. Nat. Mater. 2018, 18, 121-128. [CrossRef]

17. Taylor, R.J.E.; Li, G.R.; Ivanov, P.; Childs, D.T.D.; Roberts, T.S.; Stevens, B.J.; Harrison, B.; Sarma, J.; Babazadeh, N.; Terrnent, G.; et al. Mode Control in Photonic Crystal Surface Emitting Lasers through External Reflection. IEEE J. Sel. Top. Quantum Electron. 2017, 23, 1-8. [CrossRef] 
18. Hirose, K.; Liang, Y.; Kurosaka, Y.; Watanabe, A.; Sugiyama, T.; Noda, S. Watt-class high-power, high-beam-quality photoniccrystal lasers. Nat. Photonics 2014, 8, 406-411. [CrossRef]

19. Wang, Z.X.; Liang, Y.; Meng, B.; Sun, Y.T.; Omanakuttan, G.; Gini, E.; Beck, M.; Sergachev, I.; Lourdudoss, S.; Faist, J.; et al. Large area photonic crystal quantum cascade laser with $5 \mathrm{~W}$ surface-emitting power. Opt. Express 2019, 27, 22708-22716. [CrossRef] [PubMed]

20. Lu, H.Y.; Tian, S.C.; Tong, C.Z.; Wang, L.J.; Rong, J.M.; Liu, C.Y.; Wang, H.; Shu, S.L.; Wang, L.J. Extracting more light for vertical emission: High power continuous wave operation of $1.3-\mu \mathrm{m}$ quantum-dot photonic-crystal surface-emitting laser based on a flat band. Light Sci. Appl. 2019, 8, 1-6. [CrossRef]

21. Klehr, A.; Liero, A.; Christopher, H.; Wenzel, H.; Maassdorf, A.; Della Casa, P.; Fricke, J.; Ginolas, A.; Knigge, A. Wavelength stabilized high pulse power 48 emitter laser bars for automotive light detection and ranging application. Semicond. Sci. Technol. 2020, 35, 065016. [CrossRef]

22. Kitamura, K.; Okino, T.; Yasuda, D.; Noda, S. Polarization control by modulated photonic-crystal lasers. Opt. Lett. 2019, 44, 4718-4720. [CrossRef] [PubMed]

23. Yokoyama, M.; Noda, S. Polarization mode control of two-dimensional photonic crystal laser having a square lattice structure. IEEE J. Quantum Electron. 2003, 39, 1074-1080. [CrossRef]

24. Miyai, E.; Sakai, K.; Okano, T.; Kunishi, W.; Ohnishi, D.; Noda, S. Lasers producing tailored beams. Nature 2006, $441,946$. [CrossRef]

25. Liang, Y.; Okino, T.; Kitamura, K.; Peng, C.; Ishizaki, K.; Noda, S. Mode stability in photonic-crystal surface-emitting lasers with large k1DL. Appl. Phys. Lett. 2014, 104, 21102. [CrossRef]

26. Imada, M.; Chutinan, A.; Noda, S.; Mochizuki, M. Multidirectionally distributed feedback photonic crystal lasers. Phys. Rev. B 2002, 65, 65. [CrossRef]

27. Zhou, W.D.; Liu, S.C.; Ge, X.; Zhao, D.Y.; Yang, H.J.; Reuterskiold-Hedlund, C.; Hammar, M. On-Chip Photonic Crystal Surface-Emitting Membrane Lasers. IEEE J. Sel. Top. Quantum Electron. 2019, 25, 1-11. [CrossRef]

28. Li, Z.L.; Chang, B.H.; Lin, C.H.; Lee, C.P. Dual-wavelength GaSb-based mid infrared photonic crystal surface emitting lasers. J. Appl. Phys. 2018, 123, 093102. [CrossRef]

29. Siegman, A.E.; Townsend, S.W. Output beam propagation and beam quality from a multimode stable-cavity laser. IEEE J. Quantum Electron. 1993, 29, 1212-1217. [CrossRef]

30. Carter, W.H. Spot size and divergence for Hermite Gaussian beams of any order. Appl. Opt. 1980, 19, 1027-1029. [CrossRef] [PubMed] 